\title{
Mitochondrial DNA copy number in cervical exfoliated cells and risk of cervical cancer among HPV-positive women
}

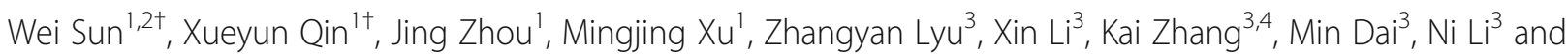
Dong Hang ${ }^{1,5^{*}}$

\begin{abstract}
Background: Although human papillomavirus (HPV) infection has been regarded as the cause of cervical cancer in over $99 \%$ of cases, only a small fraction of HPV-infected women develop this malignancy. Emerging evidence suggests that alterations of mitochondrial DNA copy number ( $\mathrm{mtCN}$ ) may contribute to carcinogenesis. However, the relationship between $\mathrm{mtCN}$ and cervical cancer remains undetermined.

Methods: The current study included 591 cervical cancer cases and 373 cancer-free controls, all of whom were infected with high-risk HPV. Relative mtCN in cervical cancer exfoliated cells was measured by qRT-PCR assays, and logistic regression analysis was performed to compute odds ratios (ORs) and 95\% confidence intervals (Cls). Interaction between mtCN and HPV types was assessed by using the Wald test in logistic regression models.

Results: HPV16, 18, 52, and 58 were the most common types in both case and control groups. Median mtCN in cases was significantly higher than that in controls (1.63 vs. 1.23, $P=0.03$ ). After adjustment for age and HPV types, the highest quartile of $\mathrm{mtCN}$ was associated with increased odds of having cervical cancer (OR=1.77, 95\% Cl=1.19, 2.62; $P<0.01)$, as compared to the lowest quartile. A dose-response effect of $\mathrm{mtCN}$ on cervical cancer was also observed $\left(P_{\text {trend }}<0.001\right)$. The interaction between mtCN and HPV types was statistically nonsignificant.
\end{abstract}

Conclusions: In women who test HPV positive, the increase of mtCN in cervical exfoliated cells is associated with cervical cancer. This suggests a potential role of $\mathrm{mtCN}$ in cervical carcinogenesis.

Keywords: Mitochondrial DNA copy number, Mitochondrion, Cervical cancer, Human papillomavirus, Case-control study

\section{Background}

Cervical cancer represents the fourth most common malignancy in women worldwide [1]. Persistent infection with a subset of human papillomavirus (HPV), termed high-risk

\footnotetext{
* Correspondence: hangdong@njmu.edu.cn

${ }^{+}$Wei Sun and Xueyun Qin contributed equally to this work.

'Department of Epidemiology and Biostatistics, School of Public Health,

Nanjing Medical University, No. 101 Longmian Ave, Jiangning District,

Nanjing 211166, China

${ }^{5}$ Jiangsu Key Lab of Cancer Biomarkers, Prevention and Treatment,

Collaborative Innovation Center for Cancer Personalized Medicine, Nanjing Medical University, Nanjing 211166, China

Full list of author information is available at the end of the article
}

types, has been recognized as the crucial cause of the disease [2]. As a primary prevention strategy, HPV vaccination against infection is safe and effective to prevent cervical intraepithelial neoplasia (CIN) and cervical cancer [3]. For women who are already infected with HPV, secondary prevention efforts including cervical cancer screening and early intervention can mitigate the incidence and mortality of cervical cancer [4]. Current guidelines for cervical screening are largely based on HPV testing and cytologic diagnosis [5]. However, because HPV infection is a very common event and approximately $90 \%$ of infections resolve spontaneously within 2 years, HPV testing is limited by a low

(C) The Author(s). 2020 Open Access This article is licensed under a Creative Commons Attribution 4.0 International License, which permits use, sharing, adaptation, distribution and reproduction in any medium or format, as long as you give appropriate credit to the original author(s) and the source, provide a link to the Creative Commons licence, and indicate if changes were made. The images or other third party material in this article are included in the article's Creative Commons licence, unless indicated otherwise in a credit line to the material. If material is not included in the article's Creative Commons licence and your intended use is not permitted by statutory regulation or exceeds the permitted use, you will need to obtain permission directly from the copyright holder. To view a copy of this licence, visit http://creativecommons.org/licenses/by/4.0/ The Creative Commons Public Domain Dedication waiver (http://creativecommons.org/publicdomain/zero/1.0/) applies to the data made available in this article, unless otherwise stated in a credit line to the data. 
positive predictive value (less than 50\%) for high-grade lesions [6]. Although cytology-based triage is recommended in cervical screening, this technique has a relatively low sensitivity and high dependence on an experienced cytologist [7]. Therefore, an investigation of new triage approaches for HPV-positive women is important to improve the identification of individuals at high risk of cervical cancer.

Mitochondrial DNA (mtDNA) is an extra-chromosomal circular, double-stranded DNA in eukaryotic cells [8]. It consists of 16.5 kilobase pairs that encode 37 genes involved in various cellular activities, including energy metabolism, free oxygen radical generation, and cell apoptosis [9]. Due to the lack of protective histones, introns, and efficient DNA repair mechanism, mtDNA is particularly vulnerable to reactive oxidative species (ROS) and other sources of genotoxic stress, which may induce mtDNA damage and copy number alterations [10]. Altered mtDNA copy number $(\mathrm{mtCN})$ could affect the expression and function of mitochondrial genes, leading to abnormal cellular metabolism and proliferation [11]. Increasing evidence suggests that $\mathrm{mtCN}$ alterations play an important role in pathogenesis of different types of cancer [12]. Compared to adjacent normal tissues, mtCN was significantly increased in head and neck cancer [13], esophageal carcinoma [14], and endometrial carcinoma tissues [15], whereas it was decreased in advanced lung cancer [16], hepatocellular carcinoma [17], gastric cancer [18], and colorectal cancer tissues [19]. Increased $\mathrm{mtCN}$ has been considered as a compensation for metabolic defects in impaired mitochondria [20]. When cancer progresses to advanced stages, cumulative damages to mitochondria may elicit mtDNA degradation and decompensation, resulting in a decrease in $\mathrm{mtCN}$ and the Warburg effect [21, 22].

High-risk HPV oncoproteins E6 and E7 can induce chronic ROS responses, which are able to promote DNA damage and malignant phenotypes of HPV-infected cells $[23,24]$. Increased ROS may also give rise to mtDNA damage and alter mitochondrial abundance in cervical cells. Therefore, we hypothesized that $\mathrm{mtCN}$ alterations are implicated in the development of cervical cancer. To our knowledge, no prior studies have assessed the association between $\mathrm{mtCN}$ and cervical cancer among HPVpositive women.

In this case-control study, we detected $\mathrm{mtCN}$ in cervical exfoliated cells collected from participants who were all high-risk HPV positive. We aimed to provide precursory evidence on the role of $\mathrm{mtCN}$ in cervical cancer and its potential as a biomarker for cervical cancer.

\section{Methods}

\section{Study participants}

This study was approved by the ethics committees of Nanjing Medical University and Cancer Institute and Hospital, Chinese Academy of Medical Sciences. All participants provided the written informed consent and thereafter underwent cytological examination. Cervical exfoliated cell specimens were collected by experienced gynecologists using cytobrushes. For those with abnormal cytology, we recommended a colposcopy, during which cervical biopsies were taken. The included cervical cancer patients were histologically confirmed and consecutively recruited from Cancer Institute and Hospital between January 2010 and July 2013, as previously described [25]. Exclusion criteria included those who had recurrent cervical cancer or a history of other malignancies, and those who had received chemo-radio therapy before specimen collection. Of the 5066 women who asked for outpatient gynecological consultation in Cancer Institute and Hospital during the same period and were free of liquid-based cytological abnormalities (atypical squamous cells of undetermined significance, ASCUS, or worse) but were high-risk HPV positive were included as cancer-free individuals. Approximately 12, 100 women who attended an outpatients appointment and had an abnormal cervical cytology were excluded. For those participants with normal cytology, a colposcopy was not routinely used unless they were HPV16 or 18-DNA positive. High-risk HPV prevalence was $97.7 \%$ $(593 / 607)$ in cervical cancer patients and 8.0\% (407/ 5066) in cancer-free individuals [25]. In the current study, all HPV16/18-positive controls accepted colposcopy and showed negative results. Due to insufficient DNA, specimens from two patients and 34 cancer-free individuals were excluded. Finally, a total of 591 cancer cases and 373 controls (all high-risk HPV positive) were included in the analysis.

\section{HPV genotyping}

The procedure for HPV genotyping has been described in detail elsewhere [26]. Briefly, total genomic DNA was isolated from cervical exfoliated cells using the QIAamp DNA Mini Kit (Qiagen, Valencia, CA, USA). To evaluate the quality of DNA samples, the $\beta$-actin gene was amplified by PCR. Only qualified samples were further tested for HPV DNA by using the HPV GenoArray Test Kit (HybriBio Ltd., Beijing, China). The method could detect a total of $21 \mathrm{HPV}$ types simultaneously, including 13 high-risk types (HPV16, 18, 31, 33, 35, 39, 45, 51, 52, 56, 58,59 , and 68), two intermediate-risk types (HPV53 and 66), and six low-risk HPV types (HPV6, 11, 42, 43, 44, and 81).

\section{Measurement of mtDNA copy number}

Relative $\mathrm{mtCN}$ in cervical exfoliated cells was determined by real-time quantitative PCR (qRT-PCR), as described in our previous study [27]. In brief, we used two pairs of specific primers that were designed to amplify the partial regions of mitochondrial subunit ND1 gene 
(MT-ND1, Forward: 5'-CCCTAAAACCCGCCACAT CT-3'; Reverse: 5'-GAGCGATGGTGAGAGCTA AGGT-3') and the single-copy nuclear gene human globulin (HGB, Forward: 5'-GAAGAGCCAAGGAC AGGTAC-3'; Reverse: 5'-CAACTTCATCCACGTTCA CC-3'), respectively. The qRT-PCR reaction was performed using the SYBR Green Realtime PCR Master Mix (Toyobo Co. Ltd., Osaka, Japan) on the 7900HT Real-Time PCR System (Applied Biosystems, CA). All assays were done in triplicates in 384-well plates, and laboratory technicians were blinded to the case-control status during the experiments. To assess the inter-plate variation in PCR efficiency, for each 384-well plate, DNA samples from five randomly selected controls were equally pooled as the reference and serially diluted 1:2 (20 to $0.625 \mathrm{ng} / \mu \mathrm{l}$ ) to produce a standard curve, which showed a high coefficient of determination (above 0.99) for each reaction. We calculated the ratio of $M T-N D 1$ to $H G B(-\mathrm{dCt})$ for each sample by subtracting the average $H G B \mathrm{Ct}$ value from the average $M T-N D 1 \mathrm{Ct}$ value. The relative ratio of $M T-N D 1$ to $H G B(-\Delta \Delta \mathrm{Ct})$ was computed by subtracting the ratio of $M T-N D 1$ to $H G B$ of the calibrator DNA from the ratio of each sample. Relative $\mathrm{mtCN}$ was calculated by using the formula $2^{-\Delta \Delta C t}$ [27]. The average inter- and intra-plate variations, determined by the measurement of quality control samples, were 1.9 and $1.0 \%$, respectively.

\section{Statistical analysis}

Pearson $\chi^{2}$ tests were used to evaluate the differences in demographic characteristics and HPV types between cases and controls. Unconditional logistic regression was performed to estimate the odds ratio (OR) and 95\% confidence intervals (CIs) for cervical cancer in each mtCN quartile, with the adjustment for age and HPV types. Statistical significance of interaction was assessed by a Wald test for the cross-product terms between mtCN and HPV types in logistic regression models. A twotailed $P$ value of less than 0.05 was considered statistically significant. All statistical analyses were conducted by using $\mathrm{R}$ (version 3.3.3).

\section{Results}

Table 1 shows the demographic and clinical characteristics of participants. In both cases and controls, HPV16, 18,52 , and 58 were the most frequent types. No statistically significant differences were observed in age, HPV18, and multiple infections between the case and control groups. However, cervical cancer patients had a higher proportion of HPV16 infection (54.65\% vs. $19.57 \%, P<0.001)$ but lower proportions of HPV52 (17.43\% vs. $27.08 \%, P<0.001)$ and HPV58 (9.31\% vs. $15.55 \%, P=0.005)$, as compared to the control group. More importantly, the median $\mathrm{mtCN}$ was higher in
Table 1 Basic characteristics of cervical cancer cases and cancer-free controls

\begin{tabular}{|c|c|c|c|}
\hline \multirow[t]{2}{*}{ Variables } & $\begin{array}{l}\text { Cases } \\
(n=591)\end{array}$ & $\begin{array}{l}\text { Controls } \\
(n=373)\end{array}$ & \multirow[t]{2}{*}{$P$} \\
\hline & N (\%) & N (\%) & \\
\hline Age, years & & & $0.36^{\mathbf{e}}$ \\
\hline$<50$ & $339(57.36)$ & $226(60.59)$ & \\
\hline$\geq 50$ & $252(42.64)$ & $147(39.41)$ & \\
\hline HPV16 & & & $<0.001^{\mathrm{e}}$ \\
\hline Negative & 268(45.35) & $300(80.43)$ & \\
\hline Positive & $323(54.65)$ & $73(19.57)$ & \\
\hline HPV18 & & & $0.43^{\mathbf{e}}$ \\
\hline Negative & $532(90.02)$ & 342(91.69) & \\
\hline Positive & $59(9.98)$ & $31(8.31)$ & \\
\hline HPV52 & & & $<0.001^{\mathrm{e}}$ \\
\hline Negative & $488(82.57)$ & $272(72.92)$ & \\
\hline Positive & 103(17.43) & $101(27.08)$ & \\
\hline HPV58 & & & $0.005^{e}$ \\
\hline Negative & $536(90.69)$ & $315(84.45)$ & \\
\hline Positive & $55(9.31)$ & $58(15.55)$ & \\
\hline Other type ${ }^{\text {a }}$ & & & $<0.001^{e}$ \\
\hline Negative & $481(81.39)$ & 239(64.08) & \\
\hline Positive & $110(18.61)$ & 134(35.92) & \\
\hline Multiple infection & & & $0.15^{\mathbf{e}}$ \\
\hline Negative & 538(91.03) & 350(93.83) & \\
\hline Positive & $53(8.97)$ & $23(6.17)$ & \\
\hline \multicolumn{4}{|l|}{ Grade $^{b}$} \\
\hline High & 27(7.99) & & \\
\hline Middle & $178(52.66)$ & & \\
\hline Low & 133(39.35) & & \\
\hline \multicolumn{4}{|l|}{ Histology ${ }^{c}$} \\
\hline Squamous & $536(94.87)$ & & \\
\hline Adeno/adenosquamous & $29(5.13)$ & & \\
\hline \multicolumn{4}{|l|}{$\mathrm{FIGO}^{d}$} \\
\hline$|/| \mid$ & 366(83.75) & & \\
\hline III/IV & $71(16.25)$ & & \\
\hline mtCN (median, quartile) & $1.63(0.59-3.43)$ & $1.23(0.53-2.76)$ & $0.03^{f}$ \\
\hline
\end{tabular}

Bold values indicate $P<0.05$

Abbreviation: HPV human papillomavirus, FIGO International Federation of Gynecology and Obstetrics, $m t C N$ mitochondrial DNA copy number a Others include HPV31, 33, 35, 39, 45, 51, 56, 59, 66, and 68

${ }^{\mathrm{b}}$ Grade information was available in 338 cervical cancer cases

${ }^{c}$ Histological information was available in 565 cases

${ }^{d}$ FIGO information was available in 437 cervical cancer cases e Derived from $x^{2}$ test

fDerived from Wilcoxon rank-sum test

cervical cancer cases than that in the controls (1.63 vs. $1.23, P=0.03)$. Most of the cases were squamous carcinoma $(94.9 \%)$ and at FIGO I/II stage (83.8\%). Figure 1 


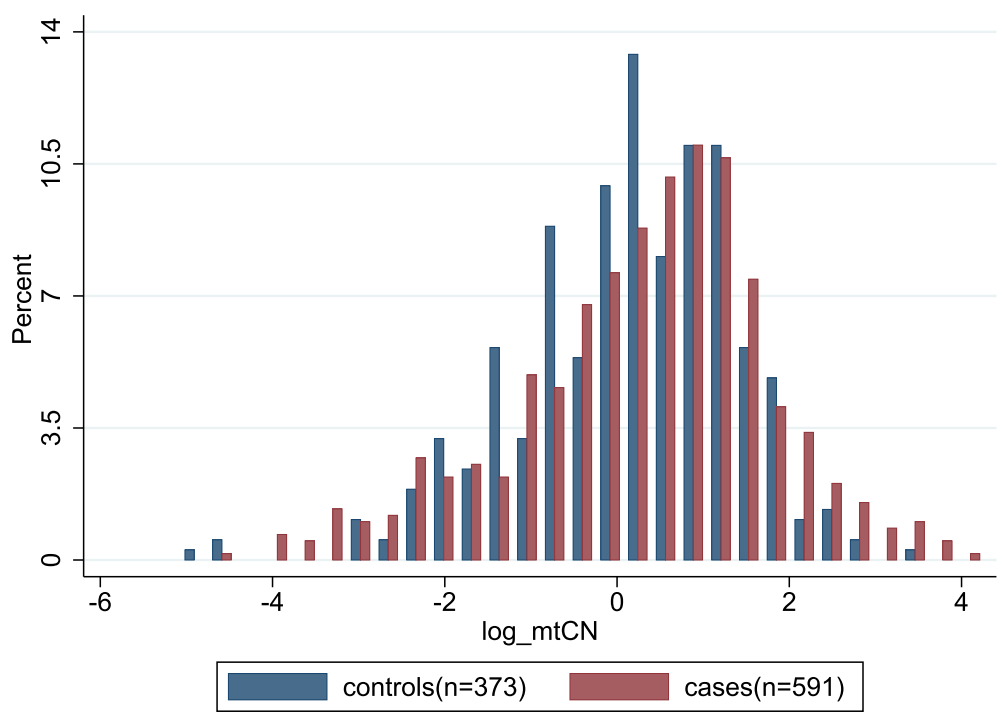

Fig. 1 Distribution of mitochondrial copy number (log-transformed) in the cases and controls

shows the distribution of $\mathrm{mtCN}$ in the cases and controls.

In Table 2, compared with the lowest quartile of $\mathrm{mtCN}$, a significantly increased odds of having cervical cancer was observed in the third $(\mathrm{OR}=1.56,95 \% \mathrm{CI}$ : $1.04,2.33 ; P=0.03)$ and fourth quartile groups $(\mathrm{OR}=$ 1.77, 95\% CI: $1.19,2.62 ; P=0.004)$. A dose-response effect of mtCN on cervical cancer was statistically significant $(P$ trend $<0.001)$.

We performed the stratified analysis by age and different HPV types (Table 3). The dose-response effect of $\mathrm{mtCN}$ on cervical cancer risk was largely consistent between subgroups, with the interaction between $\mathrm{mtCN}$ and the stratified variables statistically nonsignificant (all $P>0.05)$.

\section{Discussion}

In this study, relative $\mathrm{mtCN}$ was determined in cervical exfoliated cells from 591 cervical cancer patients and 373 cancer-free controls. We found that median mtCN in the patients was significantly higher than that in the

Table 2 Association between mitochondrial DNA copy number and cervical cancer

\begin{tabular}{llllll}
\hline $\mathrm{mtCN}$ & Cases (\%) & Controls (\%) & $\mathrm{OR}(95 \% \mathrm{Cl})^{\text {a }}$ & $P^{\text {a }}$ & $P_{\text {trend }}$ \\
\hline$\leq 0.53$ & $135(22.84)$ & $94(25.21)$ & 1.00 & & $<\mathbf{0 . 0 0 1}$ \\
$0.53-1.23$ & $110(18.61)$ & $93(24.93)$ & $1.03(0.67,1.56)$ & 0.90 & \\
$1.23-2.76$ & $154(26.06)$ & $92(24.66)$ & $1.56(1.04,2.33)$ & $\mathbf{0 . 0 3}$ & \\
$\geq 2.76$ & $192(32.49)$ & $94(25.20)$ & $1.77(1.19,2.62)$ & $\mathbf{0 . 0 0 4}$ & \\
\hline
\end{tabular}

Bold values indicate $P<0.05$

Abbreviation: $m t C N$ mitochondrial DNA copy number, $O R$ odds ratio, $C l$ confidential interval

a Derived from logistic regression with adjustment for age, HPV 16, 18, 52,58 and the other high-risk type infection status controls. After adjustment for age and HPV types, a higher level of $\mathrm{mtCN}$ remained associated with increased odds of having cervical cancer, and there was a doseresponse effect of $\mathrm{mtCN}$ on cervical cancer. The results suggest that $\mathrm{mtCN}$ alterations may be implicated in cervical carcinogenesis and might represent a potential biomarker for triage of HPV-positive women.

To date, few studies have investigated the association between mtDNA abundance and cervical cancer. Based on tissue samples, Warowicka et al. showed that total $\mathrm{mtCN}$ was cumulatively increased in high-grade squamous intraepithelial lesion $(n=30)$ and cervical cancer $(n=29)$, compared to that in low-grade lesion samples $(n=29)$ [28], whereas Kabekkodu et al. reported a lower level of $\mathrm{mtCN}$ in cervical cancer tissues $(n=20)$ than in cervicitis samples $(n=10)$ [29]. Small sample sizes and different cancer stages might partly explain the inconsistency. Moreover, neither of the studies detected HPV infection, which is a pre-requisite for cervical cancer. In fact, cervical exfoliated cells are collected in cytology-based cervical screening and may also be a source of molecular biomarkers indicative of neoplastic changes in the underlying tissue. In the current study, for the first time we determined HPV types and mtCN in cervical exfoliated cells from cervical cancer patients and healthy controls. We found that $\mathrm{mtCN}$ in cervical cells was positively associated with cervical cancer after adjustment for age and HPV types. However, given the relatively weak association with cervical cancer, a combination with other biomarkers, such as E6/E7 mRNA, p16INK4a-Ki-67, and HPV integration [30, 31], may improve the prediction of cervical cancer risk for HPV-positive women. In addition, it has been suggested that higher $\mathrm{mtCN}$ in cervical cancer tissues is associated with a reduced overall survival, implying that 
Table 3 Association between mitochondrial DNA copy number and cervical cancer

\begin{tabular}{|c|c|c|c|c|c|c|}
\hline \multirow[t]{3}{*}{ Variables } & \multicolumn{4}{|c|}{ Quartiles of $\mathrm{mtCN}{ }^{\mathrm{a}}$} & \multirow{3}{*}{$\begin{array}{l}P \\
\text { trend }\end{array}$} & \multirow{3}{*}{$\begin{array}{l}P \\
P \\
\text { interaction } \\
c\end{array}$} \\
\hline & 1st quartile & 2nd quartile & 3rd quartile & 4th quartile & & \\
\hline & Reference & OR $\left(95 \%\right.$ Cl) ${ }^{b}$ & OR $\left(95 \%\right.$ Cl) ${ }^{b}$ & OR $(95 \% \mathrm{Cl})^{\mathrm{b}}$ & & \\
\hline \multicolumn{7}{|l|}{ Age (years) } \\
\hline$<50$ & 1.00 & $0.87(0.49-1.55)$ & $1.25(0.74-2.10)$ & $1.44(0.87-2.40)$ & 0.08 & \multirow[t]{2}{*}{0.40} \\
\hline$\geq 50$ & 1.00 & $1.14(0.61-2.16)$ & $2.10(1.10-4.02)$ & $2.32(1.24-4.35)$ & 0.002 & \\
\hline \multicolumn{7}{|l|}{ HPV16 } \\
\hline Negative & 1.00 & $1.10(0.67-1.89)$ & $2.09(1.26-3.46)$ & $2.03(1.23-3.33)$ & 0.001 & \multirow[t]{2}{*}{0.21} \\
\hline Positive & 1.00 & $1.00(0.55-2.10)$ & $0.79(0.40-1.57)$ & $1.56(0.77-3.16)$ & 0.34 & \\
\hline \multicolumn{7}{|l|}{ HPV18 } \\
\hline Negative & 1.00 & $1.08(0.74-1.68)$ & $1.57(1.02-2.41)$ & $1.67(1.10-2.53)$ & 0.01 & \multirow[t]{2}{*}{0.26} \\
\hline Positive & 1.00 & $0.56(0.26-2.47)$ & $1.30(0.38-4.50)$ & 2.97(0.77-11.38) & 0.07 & \\
\hline \multicolumn{7}{|l|}{ HPV52 } \\
\hline Negative & 1.00 & $0.97(0.71-1.55)$ & $1.46(0.93-2.3)$ & $1.88(1.21-2.92)$ & 0.002 & \multirow[t]{2}{*}{0.77} \\
\hline Positive & 1.00 & $1.31(0.44-3.43)$ & $1.85(0.71-4.8)$ & $1.67(0.65-4.28)$ & 0.24 & \\
\hline \multicolumn{7}{|l|}{ HPV58 } \\
\hline Negative & 1.00 & $1.04(0.73-1.62)$ & $1.54(1.00-2.37)$ & $1.71(1.12-2.61)$ & 0.003 & \multirow[t]{2}{*}{0.65} \\
\hline Positive & 1.00 & $0.58(0.27-2.44)$ & $1.65(0.50-5.49)$ & $2.15(0.69-6.67)$ & 0.08 & \\
\hline \multicolumn{7}{|l|}{ Others } \\
\hline Negative & 1.00 & $1.22(0.66-2.12)$ & $1.14(0.68-1.90)$ & $1.80(1.10-2.96)$ & 0.03 & \multirow[t]{2}{*}{0.25} \\
\hline Positive & 1.00 & $0.81(0.57-1.63)$ & $2.40(1.22-4.71)$ & $1.94(0.99-3.81)$ & 0.003 & \\
\hline \multicolumn{7}{|c|}{ Multiple infection } \\
\hline Negative & 1.00 & $1.10(0.74-1.71)$ & $1.57(1.03-2.39)$ & $1.82(1.21-2.74)$ & 0.001 & \multirow[t]{2}{*}{0.25} \\
\hline Positive & 1.00 & $0.26(0.16-1.82)$ & $1.07(0.18-6.37)$ & $1.11(0.19-6.56)$ & 0.42 & \\
\hline
\end{tabular}

Bold values indicate $P<0.05$

Abbreviation: HPV human papillomavirus, $m t C N$ mitochondrial DNA copy number, OR odds ratio, $C l$ confidential interval

${ }^{a} Q u a r t i l e s$ of mtDNA copy number were assigned based on the distribution among controls

${ }^{b}$ Derived from logistic regression with adjustment for age, HPV 16, 18, 52, 58 and the other high-risk HPV types where appropriate

'Interaction analysis was conducted by adding a multiplicative interaction term in unconditional logistic regression models

alterations in mtDNA content might also affect cervical cancer progression [32].

Furthermore, many epidemiological studies have explored the association of $\mathrm{mtCN}$ in peripheral blood leukocytes with different types of cancer, leading to quite conflicting results [33]. A meta-analysis including 36 case-control studies showed a positive association of blood mtCN with lymphoma and breast cancer, and a negative association for hepatic carcinoma [34]. It remains unclear whether the variation of $\mathrm{mtCN}$ in blood can really reflect the etiology of a specific cancer.

High-risk HPV infection may cause a series of mitochondrial dysfunction by accelerating the production of ROS [35, 36]. Warowicka et al. observed that both $\mathrm{mtCN}$ and ROS were increased during cervical cancer development [28]. Although HPV infection usually does not mount an inflammatory response, viral oncogenes can induce a chronic ROS response. In vitro studies showed that the expression of E6*, a truncated isoform of HPV16 E6 protein, increased ROS levels in cervical cancer cells [23]. HPV16 E6 and E7 proteins can also evoke a ROS response via NOX2 oxidase activation [24]. Additionally, HPV18 E2 protein has been demonstrated to localize to mitochondrial membranes and augment mitochondrial ROS production without cell death, whereas low-risk HPV6 E2 exhibits very low interaction to mitochondria [37]. Increased ROS are thought to cause mtDNA injuries and initiate mtDNA replication to counterbalance functional defects in impaired mitochondria [38, 39]. Another possibility is that specific genetic events in the D-loop region, i.e., the non-coding mtDNA region which contains crucial elements for replication, may lead to the up-regulation of mtDNA replication [15]. Due to major roles of normal mitochondria in energy production, metabolism, and apoptosis, the accumulation of mtDNA alterations may contribute to the pathogenesis of cervical cancer.

Furthermore, several studies point out that tumor suppressor p53 can regulate $\mathrm{mtCN}$ and mitochondrial biogenesis $[40,41]$, inhibit the mitochondrial damage 
induced by ROS [42], and participate in the regulation of mitochondrial respiration [43]. High-risk HPV E6 protein has the ability to induce p53 degradation via the ubiquitin-proteasome pathway [44, 45].. Consequently, high-risk HPV E6 may disorder the p53 functions and thereby cause $\mathrm{mtCN}$ alterations. The interplay of HPV, p53, ROS, and mitochondria warrants further investigations to uncover the mechanism underlying cervical cancer.

Although this study suggests a potential role of mtCN in cervical carcinogenesis, several limitations should be addressed. First, due to the retrospective nature of a case-control study, a causal relationship remained to be established. Second, among the controls, only those with HPV16/18 positivity underwent colposcopy and showed normal findings. A possibility of cervical precursor lesions in the remaining controls cannot be completely excluded. Finally, although the interaction between $\mathrm{mtCN}$ and HPV types was statistically nonsignificant, our interaction analysis was possibly underpowered.

\section{Conclusions}

Our study indicates a positive association between $\mathrm{mtCN}$ and cervical cancer, suggesting that $\mathrm{mtCN}$ alteration may play a role in cervical carcinogenesis. Prospective studies are needed to establish the causal relationship and determine when the association becomes detectable in the pathogenetic process.

\section{Abbreviations}

HPV: Human papillomavirus; mtCN: Mitochondrial DNA copy number; OR: Odds ratio; Cl: Confidence interval; CIN: Cervical intraepithelial neoplasia; mtDNA: mitochondrial DNA; ROS: Reactive oxidative species; ASCUS: Atypical squamous cells of undetermined significance; qRT-PCR: real-time quantitative PCR; MT-ND1: Mitochondrial subunit ND1 gene; HGB: Human globulin; FIGO: International Federation of Gynecology and Obstetrics

\section{Acknowledgements}

Not applicable.

\section{Authors' contributions}

WS and XQ performed statistical analysis and drafted the manuscript. JZ, MX, $\mathrm{ZL}, \mathrm{XL}, \mathrm{KZ}$ and $\mathrm{MD}$ were involved in the acquisition, analysis, and interpretations of data. DH and NL were responsible for study design. All authors critically assessed, edited, and approved the final manuscript.

\section{Funding}

This study was supported by the National Natural Science Fund from the National Natural Science Foundation of China (81502873, 81373079, 81402147, and 81673265), Sanming Project of Medicine in Shen Zhen (No. SZSM201911015), Natural Science Foundation of Jiangsu Province for Youth (BK20150997), PUMC Youth Fund (3332016131), Natural Science Foundation of the Higher Education Institutions of Jiangsu Province (15KJB330001), Priority Academic Program for the Development of Jiangsu Higher Education Institutions (Public Health and Preventive Medicine), and Top-notch Academic Programs Project of Jiangsu Higher Education Institutions (PPZY2015A067). The funders had no role in design and conduct of the study; collection, management, analysis, and interpretation of the data; and preparation, review, or approval of the manuscript.
Availability of data and materials

All datasets analyzed in this study are available from the corresponding author on reasonable request.

\section{Ethics approval and consent to participate}

The study was approved by the ethics committees of Nanjing Medical University and Cancer Institute and Hospital, Chinese Academy of Medical Sciences. The written informed consent was obtained from all participants after risk and benefit of participation were described.

\section{Consent for publication}

Not applicable.

\section{Competing interests}

None declared.

\section{Author details}

'Department of Epidemiology and Biostatistics, School of Public Health, Nanjing Medical University, No. 101 Longmian Ave, Jiangning District, Nanjing 211166, China. ${ }^{2}$ Department of Gynecology, The First Affiliated Hospital of Nanjing Medical University, Nanjing 210036, China. ${ }^{3}$ National Office for Cancer Prevention and Control, Cancer Institute and Hospital, Chinese Academy of Medical Sciences, Beijing 100021, China. ${ }^{4}$ Department of Cancer Prevention, Cancer Institute and Hospital, Chinese Academy of Medical Sciences, Beijing 100021, China. ${ }^{5}$ Jiangsu Key Lab of Cancer Biomarkers, Prevention and Treatment, Collaborative Innovation Center for Cancer Personalized Medicine, Nanjing Medical University, Nanjing 211166, China.

Received: 20 October 2019 Accepted: 25 June 2020

Published online: 02 July 2020

\section{References}

1. Torre LA, Bray F, Siegel RL, Ferlay J, Lortet-Tieulent J, Jemal A. Global cancer statistics, 2012. CA Cancer J Clin. 2015;65(2):87-108.

2. zur Hausen H. Papillomaviruses and cancer: from basic studies to clinical application. Nat Rev Cancer. 2002;2(5):342-50.

3. Bloem P, Ogbuanu I. Vaccination to prevent human papillomavirus infections: from promise to practice. PLoS Med. 2017;14(6):e1002325.

4. Arbyn M, Raifu AO, Weiderpass E, Bray F, Anttila A. Trends of cervical cancer mortality in the member states of the European Union. Eur J Cancer. 2009; 45(15):2640-8.

5. Curry SJ, Krist AH, Owens DK, Barry MJ, Caughey AB, Davidson KW, Doubeni CA, Epling JW Jr, Kemper AR, Kubik M, et al. Screening for cervical Cancer: US preventive services task force recommendation statement. JAMA. 2018; 320(7):674-86

6. Coquillard G, Palao B, Patterson BK. Quantification of intracellular HPV E6/E7 mRNA expression increases the specificity and positive predictive value of cervical cancer screening compared to HPV DNA. Gynecol Oncol. 2011; 120(1):89-93.

7. Nanda K, McCrory DC, Myers ER, Bastian LA, Hasselblad V, Hickey JD, Matchar DB. Accuracy of the Papanicolaou test in screening for and followup of cervical cytologic abnormalities: a systematic review. Ann Intern Med. 2000;132(10):810-9.

8. Gustafsson CM, Falkenberg M, Larsson NG. Maintenance and expression of mammalian mitochondrial DNA. Annu Rev Biochem. 2016;85:133-60.

9. Papa S, Skulachev VP. Reactive oxygen species, mitochondria, apoptosis and aging. Mol Cell Biochem. 1997;174(1-2):305-19.

10. Yakes FM, Van Houten B. Mitochondrial DNA damage is more extensive and persists longer than nuclear DNA damage in human cells following oxidative stress. Proc Natl Acad Sci U S A. 1997;94(2):514-9.

11. Picard $M$, Wallace $D C$, Burelle $Y$. The rise of mitochondria in medicine. Mitochondrion. 2016;30:105-16.

12. Lu J, Sharma LK, Bai Y. Implications of mitochondrial DNA mutations and mitochondrial dysfunction in tumorigenesis. Cell Res. 2009;19(7):802-15.

13. Kim MM, Clinger JD, Masayesva BG, Ha PK, Zahurak ML, Westra WH, Califano JA. Mitochondrial DNA quantity increases with histopathologic grade in premalignant and malignant head and neck lesions. Clin Cancer Res. 2004; 10(24):8512-5. 
14. Lin CS, Chang SC, Wang LS, Chou TY, Hsu WH, Wu YC, Wei YH. The role of mitochondrial DNA alterations in esophageal squamous cell carcinomas. J Thorac Cardiovasc Surg. 2010;139(1):189-97 e184.

15. Wang Y, Liu WW, Xue WC, Tsang PC, Cheung AN, Ngan HY. The increase of mitochondrial DNA content in endometrial adenocarcinoma cells: a quantitative study using laser-captured microdissected tissues. Gynecol Oncol. 2005;98(1):104-10

16. Lin CS, Wang LS, Tsai CM, Wei YH. Low copy number and low oxidative damage of mitochondrial DNA are associated with tumor progression in lung cancer tissues after neoadjuvant chemotherapy. Interact Cardiovasc Thorac Surg. 2008;7(6):954-8.

17. Lee HC, Li SH, Lin JC, Wu CC, Yeh DC, Wei YH. Somatic mutations in the Dloop and decrease in the copy number of mitochondrial DNA in human hepatocellular carcinoma. Mutat Res. 2004;547(1-2):71-8.

18. Wen SL, Zhang F, Feng S. Decreased copy number of mitochondrial DNA: a potential diagnostic criterion for gastric cancer. Oncol Lett. 2013;6(4):1098-102.

19. Cui H, Huang $P$, Wang Z, Zhang Y, Zhang Z, Xu W, Wang X, Han Y, Guo X. Association of decreased mitochondrial DNA content with the progression of colorectal cancer. BMC Cancer. 2013;13:110.

20. Lee HC, Wei YH. Mitochondrial biogenesis and mitochondrial DNA maintenance of mammalian cells under oxidative stress. Int J Biochem Cell Biol. 2005;37(4):822-34.

21. Shokolenko I, Venediktova N, Bochkareva A, Wilson GL, Alexeyev MF. Oxidative stress induces degradation of mitochondrial DNA. Nucleic Acids Res. 2009;37(8):2539-48.

22. Warburg O. On respiratory impairment in cancer cells. Science. 1956; 124(3215):269-70

23. Williams VM, Filippova M, Filippov V, Payne KJ, Duerksen-Hughes P. Human papillomavirus type $16 \mathrm{E}^{*}$ induces oxidative stress and DNA damage. J Virol. 2014;88(12):6751-61.

24. Marullo R, Werner E, Zhang H, Chen GZ, Shin DM, Doetsch PW. HPV16 E6 and E7 proteins induce a chronic oxidative stress response via NOX2 that causes genomic instability and increased susceptibility to DNA damage in head and neck cancer cells. Carcinogenesis. 2015;36(11):1397-406.

25. Jia M, Han J, Hang D, Jiang J, Wang M, Wei B, Dai J, Zhang K, Guo L, Qi J, et al. HLA-DP is the cervical cancer susceptibility loci among women infected by high-risk human papillomavirus: potential implication for triage of human papillomavirus-positive women. Tumour Biol. 2016;37(6):8019-25.

26. Hang D, Yin Y, Han J, Jiang J, Ma H, Xie S, Feng X, Zhang K, Hu Z, Shen H, et al. Analysis of human papillomavirus 16 variants and risk for cervical cancer in Chinese population. Virology. 2016;488:156-61.

27. Zhu X, Mao Y, Huang T, Yan C, Yu F, Du J, Dai J, Ma H, Jin G. High mitochondrial DNA copy number was associated with an increased gastric cancer risk in a Chinese population. Mol Carcinog. 2017:56(12):2593-600.

28. Warowicka A, Kwasniewska A, Gozdzicka-Jozefiak A. Alterations in mtDNA: a qualitative and quantitative study associated with cervical cancer development. Gynecol Oncol. 2013;129(1):193-8.

29. Kabekkodu SP, Bhat S, Mascarenhas R, Mallya S, Bhat M, Pandey D, Kushtagi P, Thangaraj K, Gopinath PM, Satyamoorthy K. Mitochondrial DNA variation analysis in cervical cancer. Mitochondrion. 2014;16:73-82.

30. Gustinucci D, Giorgi Rossi P, Cesarini E, Broccolini M, Bulletti S, Carlani A D'Angelo V, D'Amico MR, Di Dato E, Galeazzi P, et al. Use of cytology, E6/E7 mRNA, and p16INK4a-Ki-67 to define the Management of Human Papillomavirus (HPV)-positive women in cervical Cancer screening. Am J Clin Pathol. 2016;145(1):35-45.

31. Tornesello ML, Buonaguro L, Giorgi-Rossi P, Buonaguro FM. Viral and cellular biomarkers in the diagnosis of cervical intraepithelial neoplasia and cancer. Biomed Res Int. 2013;2013:519619.

32. Feng $D$, Xu H, Li X, Wei $Y$, Jiang $H$, Xu H, Luo A, Zhou F. An association analysis between mitochondrial DNA content, G10398A polymorphism, HPV infection, and the prognosis of cervical cancer in the Chinese Han population. Tumour Biol. 2016;37(4):5599-607.

33. Mi J, Tian G, Liu S, Li X, Ni T, Zhang L, Wang B. The relationship between altered mitochondrial DNA copy number and cancer risk: a meta-analysis. Sci Rep. 2015:5:10039.

34. Hu L, Yao X, Shen Y. Altered mitochondrial DNA copy number contributes to human cancer risk: evidence from an updated meta-analysis. Sci Rep. 2016:6:35859.

35. Choi YB, Harhaj EW. Functional implications of mitochondrial reactive oxygen species generated by oncogenic viruses. Front Biol (Beijing). 2014; $9(6): 423-36$
36. Mushtaq M, Darekar S, Kashuba E. DNA tumor viruses and cell metabolism. Oxidative Med Cell Longev. 2016;2016:6468342.

37. Lai D, Tan CL, Gunaratne J, Quek LS, Nei W, Thierry F, Bellanger S. Localization of HPV-18 E2 at mitochondrial membranes induces ROS release and modulates host cell metabolism. PLoS One. 2013;8(9):e75625.

38. Wei YH, Lee CF, Lee HC, Ma YS, Wang CW, Lu CY, Pang CY. Increases of mitochondrial mass and mitochondrial genome in association with enhanced oxidative stress in human cells harboring 4,977 BP-deleted mitochondrial DNA. Ann N Y Acad Sci. 2001;928:97-112.

39. Zhou X, Wang Y, Si J, Zhou R, Gan L, Di C, Xie Y, Zhang H. Laser controlled singlet oxygen generation in mitochondria to promote mitochondrial DNA replication in vitro. Sci Rep. 2015;5:16925.

40. Saleem A, Adhihetty PJ, Hood DA. Role of p53 in mitochondrial biogenesis and apoptosis in skeletal muscle. Physiol Genomics. 2009;37(1):58-66.

41. Kulawiec M, Ayyasamy $V$, Singh KK. p53 regulates mtDNA copy number and mitocheckpoint pathway. J Carcinog. 2009;8:8.

42. Safdar A, Khrapko K, Flynn JM, Saleem A, De Lisio M, Johnston AP, Kratysberg Y, Samjoo IA, Kitaoka Y, Ogborn DI, et al. Exercise-induced mitochondrial p53 repairs mtDNA mutations in mutator mice. Skelet Muscle. 2016;6:7.

43. Matoba S, Kang JG, Patino WD, Wragg A, Boehm M, Gavrilova O, Hurley PJ, Bunz F, Hwang PM. p53 regulates mitochondrial respiration. Science. 2006; 312(5780):1650-3.

44. Scheffner M, Huibregtse JM, Vierstra RD, Howley PM. The HPV-16 E6 and E6AP complex functions as a ubiquitin-protein ligase in the ubiquitination of p53. Cell. 1993:75(3):495-505.

45. Martinez-Zapien D, Ruiz FX, Poirson J, Mitschler A, Ramirez J, Forster A, Cousido-Siah A, Masson M, Vande Pol S, Podjarny A, et al. Structure of the E6/E6AP/p53 complex required for HPV-mediated degradation of p53. Nature. 2016;529(7587):541-5.

\section{Publisher's Note}

Springer Nature remains neutral with regard to jurisdictional claims in published maps and institutional affiliations.
Ready to submit your research? Choose BMC and benefit from:

- fast, convenient online submission

- thorough peer review by experienced researchers in your field

- rapid publication on acceptance

- support for research data, including large and complex data types

- gold Open Access which fosters wider collaboration and increased citations

- maximum visibility for your research: over $100 \mathrm{M}$ website views per year

At $\mathrm{BMC}$, research is always in progress.

Learn more biomedcentral.com/submissions 